\title{
Cost-Effective Management Alternatives for Snake River Chinook Salmon: a Biological-Economic Synthesis
}

\author{
DAVID L. HALSING* AND MICHAEL R. MOORE $† \neq$ \\ ${ }^{*}$ U.S. Geological Survey, U.S. Department of the Interior, Menlo Park, CA 94025, U.S.A. \\ †School of Natural Resources \& Environment, University of Michigan, Ann Arbor, MI 48109, U.S.A.
}

\begin{abstract}
The mandate to increase endangered salmon populations in the Columbia River Basin of North America has created a complex, controversial resource-management issue. We constructed an integrated assessment model as a tool for analyzing biological-economic trade-offs in recovery of Snake River spring-and summer-run chinook salmon (Oncorhynchus tshawytscha). We merged 3 frameworks: a salmon-passage model to predict migration and survival of smolts; an age-structured matrix model to predict long-term population growth rates of salmon stocks; and a cost-effectiveness analysis to determine a set of least-cost management alternatives for achieving particular population growth rates. We assessed 6 individual salmonmanagement measures and 76 management alternatives composed of one or more measures. To reflect uncertainty, results were derived for different assumptions of effectiveness of smolt transport around dams. Removal of an estuarine predator, the Caspian Tern (Sterna caspia), was cost-effective and generally increased long-term population growth rates regardless of transport effectiveness. Elimination of adult salmon barvest had a similar effect over a range of its cost estimates. The specific management alternatives in the costeffective set depended on assumptions about transport effectiveness. On the basis of recent estimates of smolt transport effectiveness, alternatives that discontinued transportation or breached dams were prevalent in the cost-effective set, whereas alternatives that maximized transportation dominated if transport effectiveness was relatively high. More generally, the analysis eliminated 80-90\% of management alternatives from the cost-effective set. Application of our results to salmon management is limited by data availability and model assumptions, but these limitations can belp guide research that addresses critical uncertainties and information. Our results thus demonstrate that linking biology and economics through integrated models can provide valuable tools for science-based policy and management.
\end{abstract}

Keywords: Endangered Species Act, integrated assessment, Leslie matrix, salmon passage model

Alternativas Rentables para el Manejo de Salmón en el Río Snake: una Síntesis Biológica-Económica

Resumen: El mandato para incrementar las poblaciones de salmón en peligro en la Cuenca del Río Columbia de Norte América ha creado controversia en el tema de manejo de recursos. Desarrollamos un modelo de evaluación integrada como una berramienta para analizar el balance biológico-económico de la recuperación de salmón (Oncorhynchus tshawytscha) en el Río Snake. Combinamos 3 marcos de referencia: un modelo de pasadizo para salmón para pronosticar la migración y supervivencia de alevines; un modelo matricial estructurado por edades para pronosticar las tasas de crecimiento de la población de salmón a largo plazo; y un análisis de rentabilidad para determinar un conjunto de alternativas de manejo de costo mínimo para obtener tasas particulares de crecimiento poblacional. Evaluamos 6 medidas individuales de manejo de salmón y 76 alternativas compuestas de una o más medidas. Para reflejar la incertidumbre, los resultados fueron derivados de diferentes supuestos de la efectividad del transporte de alevines alrededor de las presas. La remoción de un depredador estuarino, Sterna caspia, fue rentable y en general incrementó las tasas de crecimiento poblacional

$\ddagger$ Address correspondence to M. R. Moore, email micmoore@umich.edu

Paper submitted November 27, 2005; revised manuscript accepted January 7, 2008.

338

Conservation Biology, Volume 22, No. 2, 338-350

Journal compilation (C2008 Society for Conservation Biology. No claim to original US government works.

DOI: $10.1111 / \mathrm{j} .1523-1739.2008 .00913 . \mathrm{x}$ 
a largo plazo independientemente de la efectividad de transporte. La eliminación de la captura de salmones adultos tuvo un efecto similar sobre un rango de sus estimaciones de costos. Las alternativas de manejo específicas en el conjunto rentable dependieron de los supuestos sobre la efectividad de transporte. Sobre la base de estimaciones recientes de la efectividad de transporte de alevines, las alternativas que descontinuaron el transporte o que traspasaron presas fueron prevalentes en el conjunto rentable, mientras que las alternativas que maximizaron la transportación fueron dominantes si la efectividad de transporte era relativamente alta. Más generalmente, el análisis eliminó entre 80 y 90\% de las alternativas de manejo del conjunto rentable. La aplicación de nuestros resultados al manejo de salmón está limitada por la disponibilidad de datos y los supuestos del modelo, pero estas limitaciones pueden ayudar a conducir investigación que aborde la información e incertidumbre críticas. Por lo tanto, nuestros resultados demuestran que la combinación de biología y economía por medio de modelos integrados puede proporcionar herramientas valiosas para la política y el manejo basados en ciencia la.

Palabras Clave: Acta de Especies en Peligro, evaluación integrada, matriz de Leslie, modelo de pasadizo para salmón

\section{Introduction}

Researchers are integrating biology and economics to address conservation issues. Such approaches are being applied to biodiversity conservation, selection of terrestrial reserve sites, and establishment of marine protected areas. Influential ecologists (e.g., Roughgarden 2001) and economists (e.g., Heal \& Barbier 2006) argue persuasively that ecological-economic integration is an important research frontier and essential for improving public policy. The potential scope and scale of conservation activities is vast, yet funds for conservation are limited; thus, integration of biology and economics is necessary for efficient resource allocation.

Application of the U.S. Endangered Species Act (ESA) is a case in point. The ESA requires both biological and economic information for implementation. Biological evidence guides decisions to list species as threatened or endangered, whereas economic impacts or costs must be estimated when designating critical habitat or developing recovery plans for listed species. These 2 disciplinary approaches are rarely merged into integrated frameworks for explicit assessment of trade-offs between biological and economic metrics. Several studies, however, have developed such frameworks for analyzing recovery options for particular endangered species (e.g., Montgomery et al. 1994). Here, we constructed an integrated assessment model and demonstrated its potential utility in analyzing alternatives for managing the evolutionarily significant unit (ESU) of wild Snake River spring- and summer-run (SRSS) chinook salmon (Oncorbynchus tshawytscha).

Snake River chinook salmon were listed as threatened under the ESA in 1992 (NMFS 1992). A U.S. District Court ordered the National Marine Fisheries Service (NMFS) to prepare new biological opinions on recovery options that considered breaching the lower Snake River dams ( $\mathrm{Na}$ tional Wildlife Federation et al. v. NMFS et al. 2005) and that assessed recovery options with a comprehensive analytical framework for the entire system (American Rivers et al. v. NOAA Fisheries et al. 2006). Salmon recovery remains a scientifically complex, socially contentious issue.

Our integrated assessment addressed this topic by merging 3 modeling frameworks. First, we applied the Columbia River Salmon Passage (CRiSP) model to quantify the effects of in-river salmon management measures on second-year survival rates of juvenile salmon (Anderson et al. 2002). We used these results to adjust survival-rate parameters of the second model, an agestructured matrix population model, that projects the effect of changes in life-stage-specific, survival-rate parameters on long-term annual population growth rates (Kareiva et al. 2000; McClure et al. 2003; Wilson 2003). By integrating CRiSP and matrix models, population growth rates become functions of particular management measures. Finally, a cost-effectiveness analysis merges matrixmodel outputs with cost information on management measures to determine cost-effective management alternatives: least-cost solutions to achieving specific population growth rates. Unlike a benefit-cost analysis, a costeffectiveness analysis avoids the challenge of estimating a monetary value that reflects the social benefit of salmon (Shogren et al. 1999). Instead, it takes recovery as a legal requirement and produces information on biologicaleconomic trade-offs to assist recovery decisions.

We organized the assessment around 6 management measures-removing Caspian Terns from the Columbia River estuary, eliminating salmon harvest by humans, changing smolt transportation, drawing down reservoirs, augmenting river flow, and breaching dams-and management alternatives composed of one or more management measures. One alternative served as the baseline management plan; 75 other alternatives represented alternative plans as feasible changes to that baseline.

Our research makes a methodological contribution by developing a tool to integrate biological and economic frameworks. The cost-effectiveness analysis, by determining the least-cost alternatives, eliminates ineffective alternatives from further consideration. Cost-effectiveness 
analysis also creates a systematic way to assess trade-offs between a biological metric (population growth rate) and an economic metric (cost). In particular, our analysis assesses the cost of marginal changes in growth rate, which is important information for the decision-making process given that, in a world of scarce resources, costs must be considered because "choices among species and between species and other programs must be made" (Shogren et al. 1999).

Our research offers insights into the biological and economic effectiveness of certain management measures and alternatives for SRSS chinook. Direct application of the results to salmon management, however, is limited by data availability and model assumptions. We did not consider measures addressing hatcheries or tributary habitat because of incomplete data on biological effect or cost. Some of the data on economic cost we used were de- rived from previously published cost estimates. Furthermore, matrix models are deterministic, not stochastic, and do not address density dependence. Recent stochastic, density-dependent models are available (e.g., Zabel et al. 2006). Nevertheless, our integrated assessment model can be expanded or refined as additional data or new models become available, and, importantly, it can direct researchers to topics where critical uncertainties remain for SRSS chinook salmon management.

\section{Methods}

\section{Management Measures and Alternatives}

Our assessment included 6 commonly considered management measures to improve survival rates for SRSS chinook salmon (Table 1). Four measures affect juvenile downstream migration through the hydrosystem and

Table 1. Management measures and management alternatives for Snake River spring/summer chinook salmon and their associated annual cost in millions of 2003 dollars.

\begin{tabular}{lrr}
\hline Management measure & Measure code & Cost \\
\hline Baseline hydrosystem operations & base & 0.000 \\
Breach lower Snake River dams & breach & 209.556 \\
Reservoir drawdown & draw & 169.979 \\
Flow augmentation & flow & $32.676 / 41.740^{a}$ \\
Caspian Tern removal & tern & 0.225 \\
Add McNary Dam transportation & MCN tx & 0.863 \\
Maximize 3-dam transportation operations & max tx & $-11.211 / 0.338^{a}$ \\
Discontinue smolt transportation & no tx & -2.250 \\
Mainstem harvest elimination & harvest & 4.305
\end{tabular}

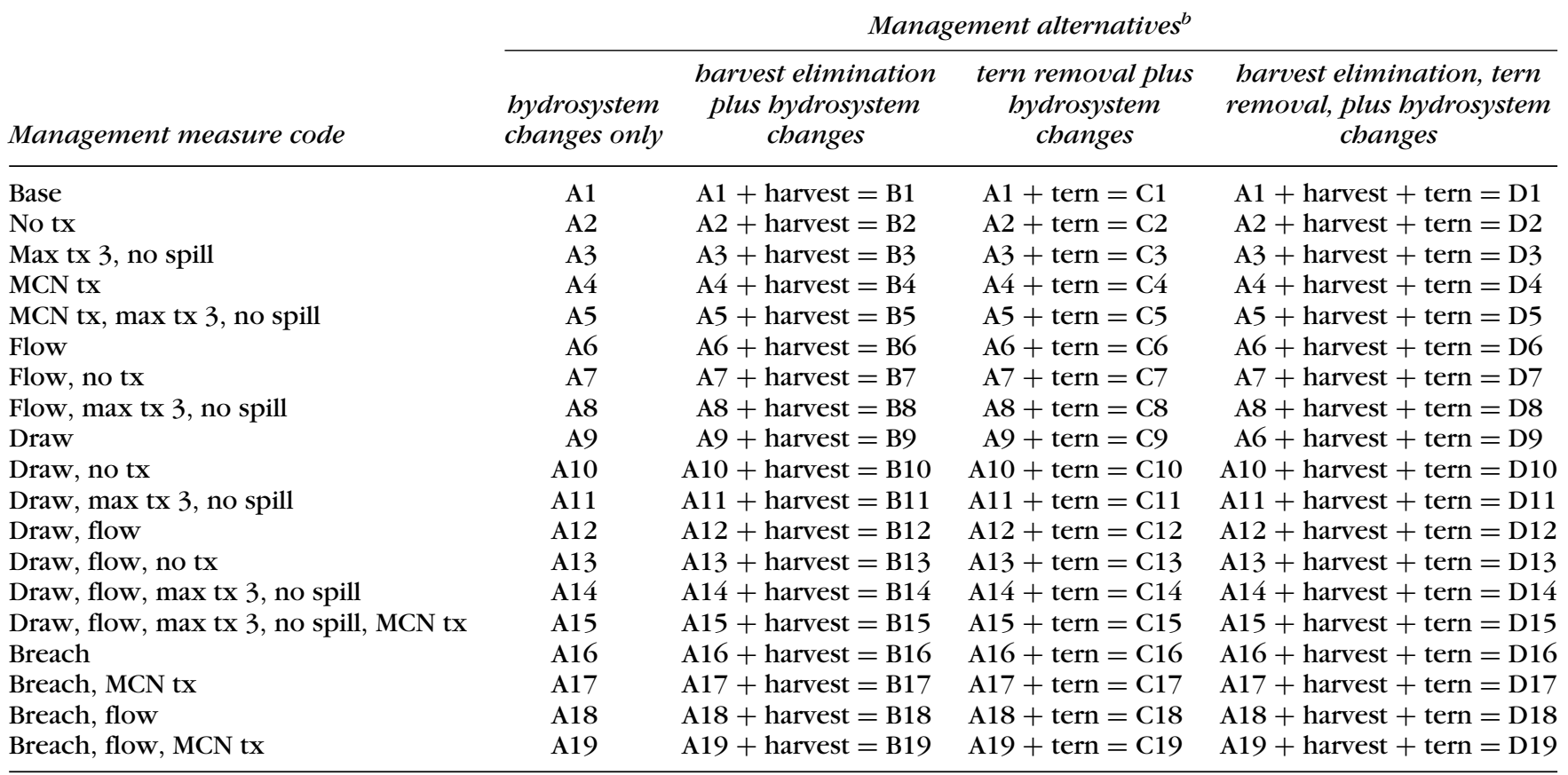

${ }^{a}$ These second entries on cost, respectively $\$ 41.74$ million and $\$ 0.338$ million, are alternate costs of flow augmentation or maximizing transportation when these measures are included in an alternative with dam breaching or reservoir drawdown. Breaching eliminates and drawdown reduces hydropower generation, which adds cost and/or reduces economic benefit in these alternatives.

${ }^{b}$ The 19 bydrosystem-only alternatives $(A 1-A 19$, with A1 = baseline) are formed from combinations of in-river management measures. These are merged singly and jointly with harvest elimination and Caspian Tern removal to form 3 other sets of 19 alternatives: B1-B19, C1-C19, and D1-D19. A management alternative's cost is the sum of the costs of its individual management measures. 
were grouped into 19 hydrosystem-only alternatives. These were combined singly and jointly with harvest elimination and removal of Caspian Terns because the latter 2 affect nonhydrosystem parts of the life cycle.

Alternative A1 was the baseline and approximated the basic salmon management program as recently as 2002, the last year for which we had the complete set of matrix parameters and available data to match the baseline. For the other alternatives, we made changes to this baseline. Alternatives A2-A19 were the hydrosystem-only alternatives. Alternatives B1-B19 and C1-C19 were these alternatives combined with harvest elimination and tern removal, respectively. Alternatives D1-D19 included the hydrosystem alternatives, tern removal, and harvest elimination. Alternative $\mathrm{B} 1$ thus represented the baseline plus harvest restriction, $\mathrm{C} 1$ the baseline plus tern removal, and D1 the baseline plus harvest restrictions and tern removal. The cost of an alternative was the sum of the costs of its measures. Table 1 lists the 76 alternatives.

\section{Biological Models}

We used a population matrix model to analyze long-term population growth (Table 2). Kareiva et al. (2000) constructed age-structured Leslie matrices to estimate the deterministic long-term mean annual population growth rate, $\lambda$, of 7 index stocks of SRSS chinook salmon, for which previous research and data have been published. We recreated these matrices and calculated $\lambda$ values, making $\lambda$ a metric with which to evaluate projected management outcomes. Lambda is a transparent and direct product of population matrices, which, although imperfect, are frequently used in academic research and management applications for salmonids. A $\lambda>1$ implies a deterministic population increase, whereas $\lambda<1$ projects the population will become extinct, although with $\lambda$ close to 1 and high enough abundance, the population's shortterm extinction risk could be low. The Kareiva et al. matrices were parameterized for return years 1995-1999, the lowest on record, and a data set from a longer time span would yield higher $\lambda s$. Still, the $\lambda$ s derived from this model will reflect relative changes well.

To simulate outcomes of management measures other than the baseline, we estimated changes in one or more of the matrix parameters that would result from these measures. The measures for which we had data to support this approach were those affecting smolt survival during downstream migration and in the Columbia River estuary and adult survival during upstream migration. Secondyear survival rate, $s_{2}$, was

$$
s_{2}=\left[z s_{z}+(1-z) s_{d}\right] s_{e},
$$

where $s_{e}$ is the estuarine survival rate, $s_{d}$ is the in-river migration survival rate, $z$ is the proportion of migrating smolts collected for transport below Bonneville Dam, and $\boldsymbol{s}_{z}$ is their survival rate during transport. A measure designed to improve downstream survival would change one or more of the bracketed parameters. We consolidated the bracketed terms in Eq. 1 into a single variable, the "net downstream survival rate," or $s_{d \text { net }}$, which is equivalent to the combined survival rate below Bonneville Dam.

We used the CRiSP model (Anderson et al. 2002) to simulate $\boldsymbol{s}_{d \text { net }}$. The CRiSP estimates survival rates through dams and reaches, and numbers of smolts collected and delivered below Bonneville. Multiplied by the $s_{e}$ value, CRiSP output for $s_{d \text { net }}$ yields $s_{2}$ and thus becomes input to the matrix.

Our parameterization of CRiSP to match the baseline included transporting $71-74 \%$ of all smolts and lowering

Table 2. Structure of demographic matrices and baseline parameter values for female Snake River spring/summer run chinook salmon* .

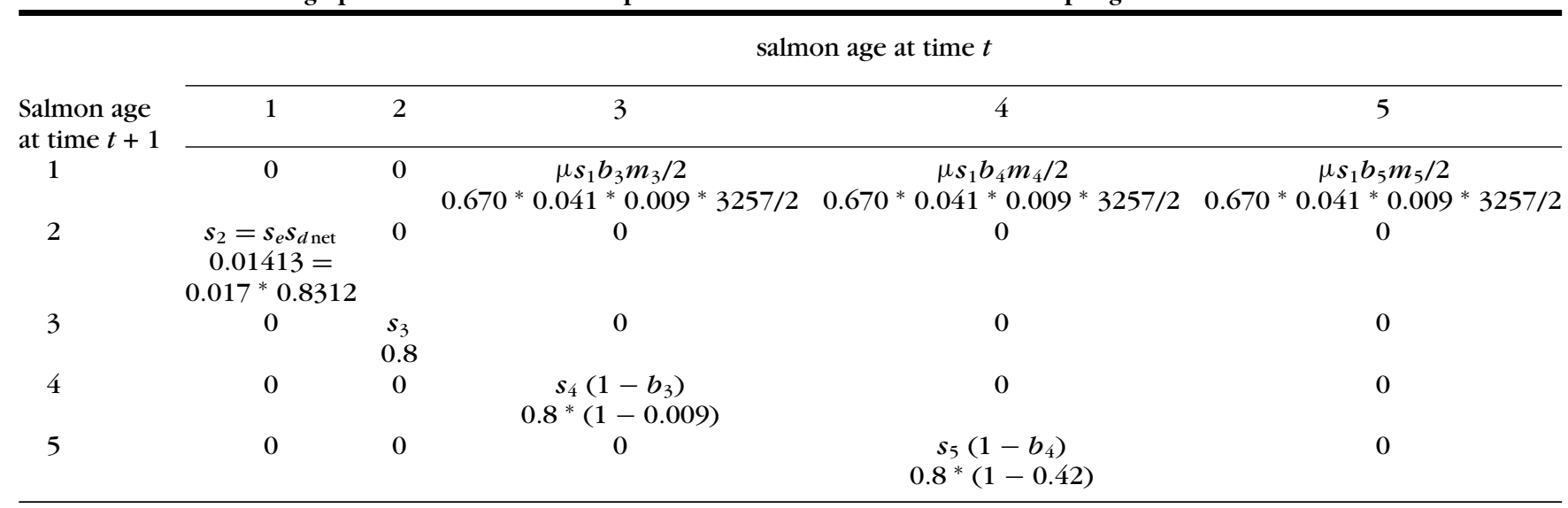

${ }^{*}$ Terms in the matrix population model are defined as follows: $\mathrm{s}_{\mathrm{x}}$, probability of survival from age $(\mathrm{x}-1)$ at time $\mathrm{t}$ to age $\mathrm{x}$ at time $\mathrm{t}+1 ; \mathrm{b}_{\mathrm{x}}$, propensity to breed at age $\mathrm{x} ; \mu$, survival during upstream migration; $\mathrm{m}_{\mathrm{x}}$, number of eggs per female spawner of age $\mathrm{x}$. Parameter $\mu$ is defined as $\mu=\left(1-\mathrm{h}_{m s}\right) \mathrm{s}_{m s}\left(1-\mathrm{h}_{s b}\right) \mathrm{s}_{s b}$, where $\mathrm{h}_{m s}$ is the harvest rate in the mainstem of the Columbia River, $\mathrm{s}_{m s}$ is the survival rate of unharvested spawners from Bonneville Dam to their spawning basin, $\mathrm{h}_{s b}$ is the harvest rate in the subbasin, and $\mathrm{s}_{\text {sb }}$ is the survival rate of unbarvested adults in the subbasin before spawning. Here, parameter $\mu=0.670=(1-0.062) *(0.794 *(1-0) * 0.9$. 
reservoirs to minimum operating pools during migration. For 6 of 7 index stocks, our baseline $\lambda$ was within \pm 0.003 of that reported in Kareiva et al. (2000), and the seventh, Marsh Creek, was within \pm 0.006 . We adjusted the baseline to reflect recent expansion of the Northern pikeminnow (Ptychocheilus oregonensis) removal program, which substantially decreased these salmon predators near the Snake and Columbia river dams. We reduced their density by $50 \%$ in CRiSP, raising baseline $\lambda s$ slightly. Further reductions appear biologically infeasible even with higher effort (Radtke et al. 2004). The CRiSP specifications are available from the authors.

Next, we generated CRiSP outputs for each management alternative. We simulated results for 4 index stocks-Imnaha River, Marsh Creek, Minam River, and Poverty Flat. Each stock was analyzed individually, but because of space considerations and because absolute changes in results are similar across stocks, results are reported mainly for the Minam River stock (complete results and matrix parameters are available from the authors).

We entered the $s_{d \text { net }}$ values from CRiSP into the matrices. In addition, for those management alternatives with harvest elimination, we adjusted adult mainstem harvest rates $\left(\boldsymbol{b}_{\mathrm{ms}}\right)$ to zero, which increased the rates of adult salmon reaching spawning grounds $(\mu)$. For dambreaching alternatives, we increased adult upstream migration survival $\left(s_{\mathrm{ms}}\right)$ from its baseline of 0.794 to 0.913 , following Kareiva et al. (2000). For alternatives with Caspian Tern removal, we increased the estuarine sur$\operatorname{vival}\left(s_{e}\right)$ rate from 0.017 to 0.018 with the same data and methods as Roby et al. (2003). Finally, we calculated $\lambda$ for all 76 alternatives.

The analysis was expanded to account for 2 biological uncertainties, delayed differential transportation mortality $(D)$ and latent mortality attributable to the hydrosystem. The $D$ arises from juvenile salmon transportation. Evidence indicates that estuary and ocean survival rates may be lower for transported smolts than in-river migrants, although the precise period in which the difference arises is unclear (Marmorek \& Peters 1998; Budy et al. 2002; Wilson 2003). Although smolt survival during transport is estimated at $98 \%$, they may not do as well as in-river migrants in later life stages (Kareiva et al. 2000; Wilson 2003). A delayed $D$ value is the ratio of the rates of survival and return of transported and untransported fish. If $D=1.0$, then the 2 groups are equal, and if $D=$ 0.5 , then transported fish return at half the rate of in-river migrants. This uncertainty is critical because the current management program transports over $70 \%$ of migrating smolts (Williams et al. 2005). Williams et al. (2005) most recently estimated that the geometric mean $D$ for SRSS chinook was 0.553 . We addressed this uncertainty by investigating $4 \mathrm{D}$ values: 0.553 (Williams et al. 2005), 0.7 (Kareiva et al. 2000), and 1.0 and 0.4 to bracket the high and low ends.
To configure the matrices for different $D$ values, we increased $s_{e}$ as needed to make $s_{2}$ equal in the baseline across each $D$-value assumption (Wilson 2003). This held $\lambda$ constant, but reallocated total mortality to different life stages. To model the effects of $D$ in each management alternative, we multiplied the number of smolts delivered below Bonneville by $D$ and added this value to the number of surviving in-river migrants. Thus, we defined $s_{d \text { net }}$ as

$$
s_{\text {net }}=\left[z s_{z} D+(1-z) s_{d}\right]
$$

This expression for $s_{d \text { net }}$ forms Eq. 3 and is input to the matrix:

$$
s_{2}=\left[s_{\text {net }}\right] s_{e} .
$$

This generated $\lambda \mathrm{s}$ for each management alternative under the 4 tested $D$ values.

Another uncertainty required other adjustments. Latent mortality from passing through the hydrosystem is manifested in a later life stage (Kareiva et al. 2000). This effect, distinct from $D$, implies that some mortality observed in the estuary or ocean comes indirectly from the reduced fitness of smolts from their downstream migration. Furthermore, adult migration is more difficult, and so some adult subbasin mortality should be reallocated to the mainstem. Budy et al. (2002) demonstrate numerous mechanisms to explain and quantify this delayed mortality. Results of recent research (ISAB 2007) show latent mortality is unquantifiable and highly uncertain. Nevertheless, to examine latent mortality in breach alternatives, following Kareiva et al., we increased adult mainstem survival, shifted some estuarine mortality to downstream migration (increasing the $s_{e}$ value), applied the 3\% latent mortality effect to the original parameters, scaled them to each $D$ value, modified the matrices, and calculated new $\lambda$ s.

\section{Cost-Effectiveness Analysis}

We defined a cost-effective salmon management alternative as the least-cost way to achieve a certain $\lambda$. We found a set of cost-effective alternatives within the range of observed $\lambda$ values by setting different levels of $\lambda$ within the range and repeatedly finding the least-cost way to achieve those $\lambda \mathrm{s}$.

For a given stock and $D$ value, each management alternative was defined by a $\lambda$-cost pair of values. We sorted the 76 alternatives by descending $\lambda$ value and identified the highest value of $\lambda$ as the most expensive cost-effective alternative. We determined the second cost-effective alternative by identifying the next alternative on the list that had a lower $\lambda$ value and a lower cost than the first alternative. One or more "lower $\lambda$, higher cost" alternatives were eliminated as inferior. We repeated this process until the entire list was exhausted to identify the set of cost-effective alternatives. 
More formally, a cost-effective alternative was found by solving

$$
\min _{i \in I} c_{i} \text { subject to } \lambda_{i} \geq \lambda^{0}
$$

where $I=\{i \mid i=1, \ldots, n\}$ is the index set of $n$ management alternatives, $c_{i}$ is the cost of alternative $i$ (derived from the sum of its management measures), $\lambda_{i}$ is the mean annual population growth rate of alternative $i$, and $\lambda^{0}$ is a growth-rate constraint. We repeatedly reset $\lambda^{0}$ and applied Eq. 4 until the set of cost-effective alternatives was found for the $n$ alternatives.

The cost-effectiveness analysis produced 2 analytical insights. First, it identified alternatives that were not leastcost solutions ("cost-ineffective" alternatives). Second, it generated information on trade-offs between $\lambda$ and cost for alternatives within the cost-effective set.

\section{Cost Estimates}

The baseline alternative provides several goods and services: hydropower, inland navigation, irrigation, recreation, and salmon management measures. Economic cost of other management alternatives was measured relative to the baseline alternative's costs and benefits. We included direct costs (real expenditures; e.g., cost to physically breach dams) and opportunity costs (monetary values of foregone goods and services; e.g., reduced hydropower generation). Costs were converted to 2003 U.S. dollars. We used a 3\% discount rate to convert dollar values from different time periods to a common metric, present-value dollars. This rate represented a risk-free, inflation-free interest rate.

\section{CASPIAN TERN REMOVAL}

Expanding the existing tern-removal program (U.S. Fish and Wildlife Service 2005) could potentially reduce tern predation by $50 \%$ relative to the baseline alternative. This would require additional capital, annual operating, and sporadic monitoring costs. On an annualized basis, these costs are $\$ 135,044, \$ 76,699$, and $\$ 12,811 /$ year, respectively, under a 25-year project life cycle (U.S. Fish and Wildlife Service 2005). We summed these costs and rounded to an estimate of $\$ 225,000 /$ year.

\section{HARVEST ELIMINATION}

Eliminating mainstem harvest of wild adult SRSS chinook salmon would prohibit all fishing for wild and hatchery stocks. Although not an often-discussed management action, this conceptually important option would entail cessation of tribal harvest. To reflect uncertainty in these costs, we applied a range of costs per fish to purchase treaty-based fishing rights. The low value (\$129/fish) applied a net economic value of recreational fishing to tribal harvest (USACE 2002). The midrange and high val- ues were $\$ 1290$ and $\$ 2580 /$ fish. We used a very high number-infinity-to reflect the perspective that tribal harvest may be priceless, due to the cultural importance of salmon to the affected tribes. Harvest elimination would never be cost-effective if the tribes were not willing sellers (infinite value).

On the basis of recent run sizes, catch rates, net economic values in commercial and sport SRSS fisheries, and tribal figures (USACE 2002; JCRMS 2006), the total annual cost of harvest elimination was $\$ 520,208$ at the lowest, $\$ 4,304,647$ midrange, and \$8,509,579 at the highest. We used the midrange cost as the base case and the other figures in the cost-effectiveness sensitivity analysis.

\section{JUVENILE SALMON TRANSPORTATION}

In the baseline, smolts were collected for transport at 3 lower Snake River dams. Three transportation options were modeled: discontinuing transport, maximizing transport at these dams, and adding transport at McNary Dam on the lower Columbia River. To estimate these costs, we started with an estimate for the transport program of \$2.5 million/year in 1995 U.S. dollars (U.S. Department of Energy et al. 1995) and assumed that these costs were divided equally among the 4 dams where transportation originally occurred (operations have since ceased at McNary Dam). This yielded a cost per dam, including reinitiating transportation at McNary Dam, of \$0.75 million/year in 2003 dollars. The 2002 Environmental Impact Statement (EIS) on lower Snake River salmon migration (USACE 2002) does not update these costs.

Discontinuing transport at the 3 dams would save \$2.25 million/year. Maximizing transport, instead, would involve transporting every smolt possible-about 9095\% of them. Lacking specific cost estimates, we assumed a $15 \%$ increase of $\$ 0.34$ million/year from additional operating and fixed costs.

Maximizing transport has a second effect. Typically, water spills are undertaken to send smolts over spillways and avoid turbine-related mortality. Spill is unnecessary when transportation is maximized because all smolts are diverted. This increases water for hydropower, which has a direct benefit in power output of an estimated \$9.4 million/year (USACE 2002) and an indirect benefit of avoided pollution emissions at fossil-fueled power plants of an estimated \$2.151 million/year. Consequently, the net effect of maximizing transportation was a benefit of $\$ 11.211$ million/year. Spill is incompatible with dam breaching or reservoir drawdown (described later), so this extrahydropower benefit was not realized in alternatives with these combinations.

\section{RESERVOIR DRAWDOWN}

Speeding migration by lowering 4 lower Snake River reservoirs by 35 feet $(10.7 \mathrm{~m})$ for 4.5 months each year 
would be more costly than current drawdown practices. Huppert (1999) estimates these increased costs at \$157 million/year in 2003 dollars. Also, we assumed replacing existing smolt bypass screens with collection systems for a lower river would require expenditures similar to the extended-submersible traveling screens that improved the original bypass systems. These were estimated at $\$ 1.985$ million/year for 3 dams (Huppert et al. 1996). These revisions would be necessary at all 4 lower Snake River dams, so the cost was increased by $33 \%$ to $\$ 3.37$ million/year and added to other drawdown costs. Newer estimates are unavailable because the 2002 EIS did not assess the augmented drawdown. Finally, replacement electricity for drawdown's foregone hydropower increases pollution emissions. These were monetized at rates of $\$ 3.85 / \mathrm{t}$ of carbon dioxide and $\$ 146 / \mathrm{t}$ of sulfur dioxide, for an estimated cost of $\$ 9.609$ million/year. The total cost of drawdown was $\$ 169.979$ million/year.

\section{FLOW AUGMENTATION}

Aiding migration by augmenting flow with water from upstream reservoirs would reduce water for irrigated agriculture. The cost of 123,444 hectare-meters (ham)/year (1 million acre-feet [maf])/year) of flow augmentation was measured as a net cost because it consisted of 2 components: the cost of acquiring water and the benefit of generating hydropower at downstream dams with the additional flow. On the basis of acquisitions to meet previous targets, water prices ranged from $\$ 81 / \mathrm{ham}$ to $\$ 413 /$ ham (U.S. Department of the Interior 2003). We adjusted these figures by a factor of 2.5 to account for an upward-sloping supply function (Aillery et al. 1999; U.S. Department of the Interior 1999) and converted to 2003 dollars. The midpoint of this range, $\$ 616 /$ ham, was similar to previous estimates of the unit cost of water acquisition (Huppert et al. 1996).

Power production from flow augmentation has an estimated value of $\$ 30.34 / \mathrm{ham}$ when the average electricity price is 2 cents/kilowatt-hour (kWh) (Huppert et al. 1996). We adjusted this number by an updated average electricity price, 2.4 cents/kWh (USACE 2002), converted to 2003 dollars, and estimated benefits of power from flow augmentation at $\$ 348 / \mathrm{ham}$. The net unit cost of flow augmentation was the difference between water acquisition and power generation, or $\$ 267 / \mathrm{ham}$. Acquiring 123,444 ham thus cost an estimated $\$ 33$ million/year. This converts to $\$ 32.676$ million/year when adjusted for avoided pollution emissions.

Nevertheless, if flow augmentation were combined with breaching or drawdown, the added flow would not generate hydropower at the lower Snake River dams, but would at the dams on the upper Snake and lower Columbia rivers. We used estimates of power production by region under flow augmentation (Huppert et al. 1996), and the benefit of power decreased from $\$ 348$ to $\$ 275 /$ ham. With this adjustment the unit cost of flow augmentation increased to $\$ 340 / \mathrm{ham}$. Acquiring 123,444 ham costs $\$ 42$ million/year in these alternatives. This converts to $\$ 41.74$ million/year when adjusted for avoided pollution emissions.

\section{DAM BREACHING}

Breaching the lower Snake River dams would require a direct capital cost and opportunity costs from reduced hydropower generation, irrigation water, commercial barging, and reservoir-based recreation. Benefits would accrue from avoided dam-maintenance costs and increases in river-based recreation. Previous estimates of these costs and benefits (USACE 2002) applied discount rates of $0 \%, 4.75 \%$, and $6.875 \%$. We interpolated from these estimates to develop a 3\% discount rate. The cost of breaching the 4 dams was $\$ 191.525$ million/year at this rate. In addition, breaching eliminated smolt transportation costs, which our calculations reflect. Finally, the replacement power generated estimated emissions of 4.6 million tons of carbon dioxide/year and 2200 tons of sulfur dioxide/year (USACE 2002), which translates into an estimated cost of $\$ 18.031$ million/year. The total cost of breaching was $\$ 209.556$ million/year.

\section{Results}

\section{Biological Analysis}

Results are reported primarily for the Minam River index stock because results for other index stocks were similar in magnitude and are available from the authors.

In general, few individual management measures or alternatives produced $\lambda>1$, regardless of $D$ value (Table 3). Parameterizations with data from other years would generate higher initial $\lambda s$, but would yield similar changes in $\lambda$. Tern removal and harvest elimination were the only measures that markedly increased $\lambda$ regardless of $D$ value. Tern removal increased $\lambda$ relative to baseline by $1.25 \%$, $0.75 \%, 0.7 \%$, and $0.61 \%$ for $D=1.0,0.7,0.553$, and 0.4 , respectively. Harvest elimination brought a $1.4 \%$ increase regardless of $D$ value. Smaller gains $(<0.5 \%)$ came from reservoir drawdown, regardless of $D$ value.

The effectiveness of hydrosystem measures depended on $D$ value and on the CRiSP structure and parameterization. Dam breaching had a substantial positive effect on $\lambda$ when $D$ was low $(17.5 \%, 11.49 \%$, and $7.04 \%$ for $D$ $=0.4,0.553$, and 0.7 , respectively). Yet, when $D=1.0$, the $\lambda$ gain from breaching shrank to $0.32 \%$. Maximizing transportation helped when $D$ was high (1.94\% increase at $D=1.0)$, but hurt when $D$ was low $(-2.23 \%$ at $D=$ 0.4 and $-0.43 \%$ at $D=0.553$ ). Eliminating transportation had the reverse effect; $\lambda$ increased by $3.14 \%$ with $D=0.553$ and $8.67 \%$ with $D=0.4$, but decreased by 
Table 3. Results for individual management measures for the Minam River index stock of Snake River spring/summer run chinook salmon.*

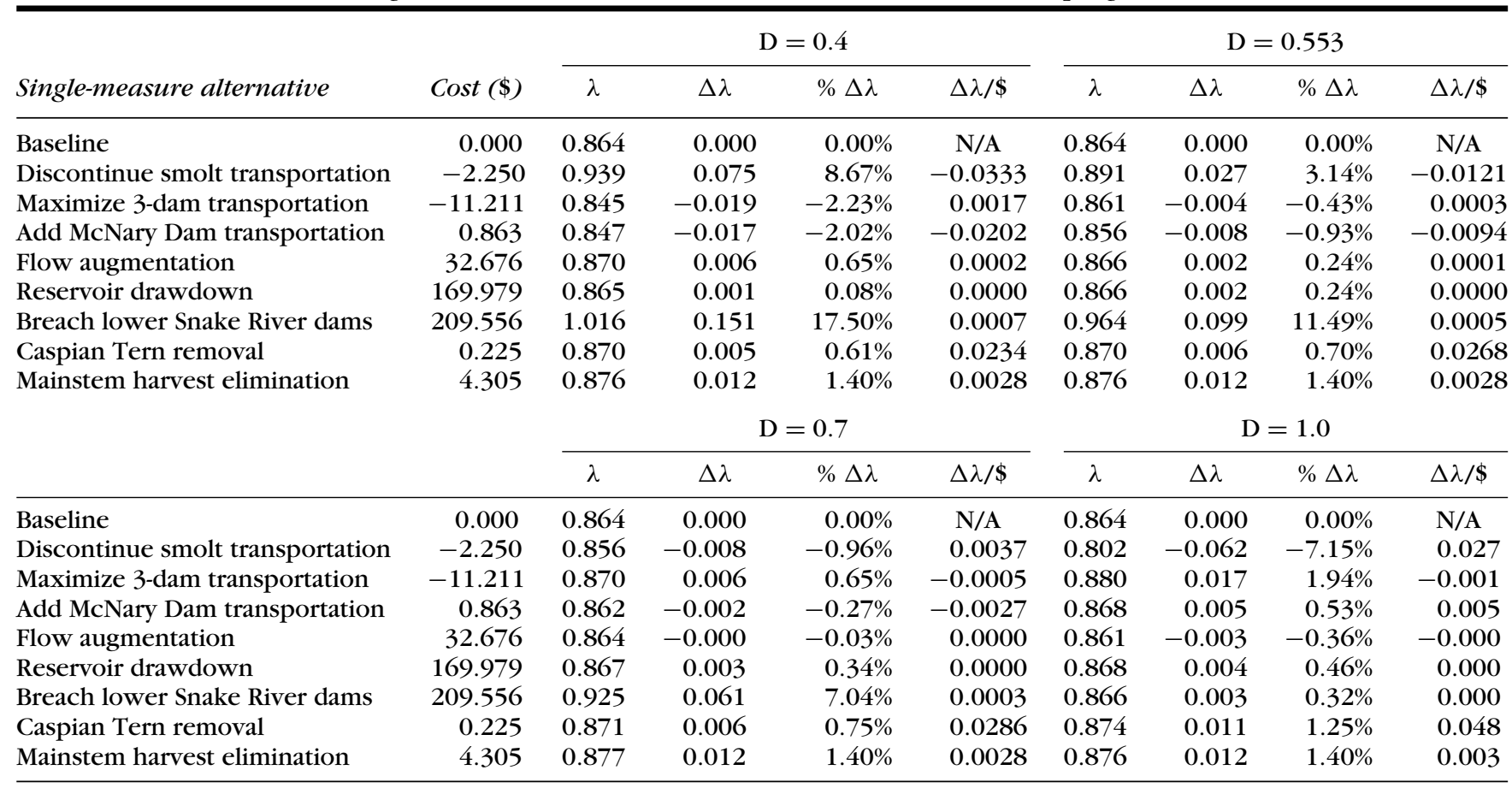

*Annual cost is in millions of 2003 dollars. The $\mathrm{D}$ is delayed differential transportation mortality, the ratio of survival-and-return rates for smolts that were transported around dams to those that migrated downstream in the river. Lambda ( $\lambda$ ) is the mean annual population growth rate arising from a management alternative. The $\Delta \lambda / \$$ is negative for some management measures, either because they have lower costs or produce a lower $\lambda$ than the baseline alternative $A 1$.

7.15\% when $D=1.0$. Impacts of adding McNary Dam transportation or flow augmentation depended similarly on $D$ value. They ranged from $-2.02 \%$ to $0.53 \%$ for McNary Dam transportation and from $-0.36 \%$ to $0.65 \%$ for flow augmentation.

Latent hydrosystem mortality affected dam-breaching management alternatives. With an assumed effect of 3\%, $\lambda>1$ in every dam-breaching alternative (A16-A19) for the Minam River stock; $\lambda$ increased by $15.8-16.9 \%$ when $D=0.553$ and by $20.9-22.4 \%$ when $D=1.0$. Other breach alternatives (B16-B19, C16-C19, and D16-D19) brought similar increases, as did breach alternatives for other index stocks.

\section{Cost-Effectiveness Analysis}

Four general findings emerged from the cost-effectiveness analysis. First, the results of the analysis showed that a majority of the feasible alternatives were costineffective: of the 76 alternatives, $62(82 \%)$ were eliminated as ineffective when $D=0.553$ (Table 4) or $D=$ 0.4 . When $D=1.0,66$ (87\%) were eliminated, and 65 (86\%) were eliminated when $D=0.7$. Each eliminated alternative was dominated by an alternative that produced a given $\lambda$ value at a lower cost. Figure 1 illustrates this for $D=0.553$.

Interestingly, with the available data and models, the baseline alternative was not cost-effective. It was domi- nated by alternatives that added Caspian Tern removal and maximized smolt transportation, which reduced cost and exceeded the baseline $\lambda$ of 0.864 (Table 4).

Second, although a robust set of cost-effective alternatives exists, the particular alternatives in the set differed by $D$ value. When $D=0.553$, cost-effective management alternatives clustered into 4 distinct groups. At the cheaper and less biologically effective end were several alternatives that counterintuitively maximized smolt transportation (alternatives $\mathrm{A} 3, \mathrm{C} 3, \mathrm{~B} 3$, and $\mathrm{D} 3$ ). These produced small increases in $\lambda$ (or even a decrease, in A3), yet were cost-effective because their cost was negative (they increased hydropower by reducing spill), and they were combined in alternatives with tern removal and/or harvest elimination. A second cluster involved alternatives that discontinued smolt transportation (A2, B2, C2 and D2). These reached $\lambda s$ of 0.9 at low cost. A third cluster of higher-cost alternatives extended D2 (discontinue transportation, add tern removal, add harvest elimination) by adding either flow augmentation (D7) or reservoir drawdown (D10). A fourth cluster involved dam-breaching alternatives (A16, C16, B16, and D16), which were the costliest yet most biologically effective alternatives $(\lambda=0.984$ for D16).

Clear differences occurred with $D=1.0$. Here, alternatives that maximized smolt transportation (alternatives $\mathrm{A} 3, \mathrm{C} 3, \mathrm{C} 5, \mathrm{~B} 3, \mathrm{D} 3, \mathrm{D} 5$, and D11) produced higher $\lambda \mathrm{s}$, 
Table 4. Complete annual cost and $\lambda$ results, in order of decreasing $\lambda$ values, for the $\mathbf{7 6}$ management alternatives for Minam River index stock of Snake River spring/summer run chinook salmon with $D=0.553 .^{a}$

\begin{tabular}{|c|c|c|c|c|c|c|c|c|c|c|c|}
\hline $\mathrm{D} 16^{b}$ & 211.836 & 0.984 & $\mathrm{D} 2^{b}$ & 2.280 & 0.910 & D14 & 205.038 & 0.881 & $\mathrm{C} 1$ & 0.225 & 0.870 \\
\hline $\mathrm{B} 16^{b}$ & 211.611 & 0.977 & B10 & 172.034 & 0.909 & D15 & 205.900 & 0.880 & C11 & 158.993 & 0.869 \\
\hline B18 & 253.351 & 0.977 & B7 & 34.731 & 0.904 & D8 & 25.995 & 0.879 & B4 & 5.167 & 0.868 \\
\hline $\mathrm{C} 16^{b}$ & 207.531 & 0.970 & $\mathrm{~B} 2^{b}$ & 2.055 & 0.904 & $\mathrm{D} 3^{b}$ & -6.681 & 0.879 & C15 & 201.596 & 0.868 \\
\hline A18 & 249.046 & 0.964 & C7 & 30.651 & 0.898 & B1 & 4.305 & 0.876 & A9 & 169.979 & 0.866 \\
\hline D17 & 212.698 & 0.943 & $\mathrm{C} 2^{b}$ & -2.025 & 0.898 & B6 & 36.981 & 0.876 & A6 & 32.676 & 0.866 \\
\hline D19 & 254.438 & 0.943 & A13 & 209.469 & 0.897 & C12 & 211.944 & 0.875 & $\mathrm{C} 5$ & -10.124 & 0.866 \\
\hline B17 & 212.473 & 0.937 & A10 & 167.729 & 0.896 & B14 & 204.813 & 0.875 & $\mathbf{A} 1^{c}$ & 0.000 & 0.864 \\
\hline B19 & 254.213 & 0.937 & A7 & 30.426 & 0.892 & B11 & 163.073 & 0.875 & $\mathrm{~A} 14^{d}$ & 200.508 & 0.863 \\
\hline $\mathrm{C} 17$ & 208.394 & 0.930 & $\mathrm{~A} 2^{b}$ & -2.250 & 0.891 & D4 & 5.392 & 0.874 & $\mathrm{~A} 11^{d}$ & 158.768 & 0.863 \\
\hline $\mathrm{D} 10^{b}$ & 172.259 & 0.915 & B12 & 216.024 & 0.881 & C6 & 32.901 & 0.872 & $\mathrm{~A} 5^{d}$ & -10.349 & 0.860 \\
\hline $\mathrm{D} 7^{b}$ & 34.956 & 0.911 & C14 & 200.733 & 0.881 & B5 & -6.044 & 0.872 & $\mathrm{~A} 4^{d}$ & 0.863 & 0.856 \\
\hline
\end{tabular}

${ }^{a}$ Cost is in millions of 2003 dollars.

${ }^{b}$ Designates a cost-effective management alternative: one that achieves a particular $\lambda$ gain at a lower cost than any other alternative.

${ }^{c}$ Designates the baseline management alternative, which is not cost effective.

${ }^{d}$ Designates a management alternative with a reduction in $\lambda$ relative to the baseline.

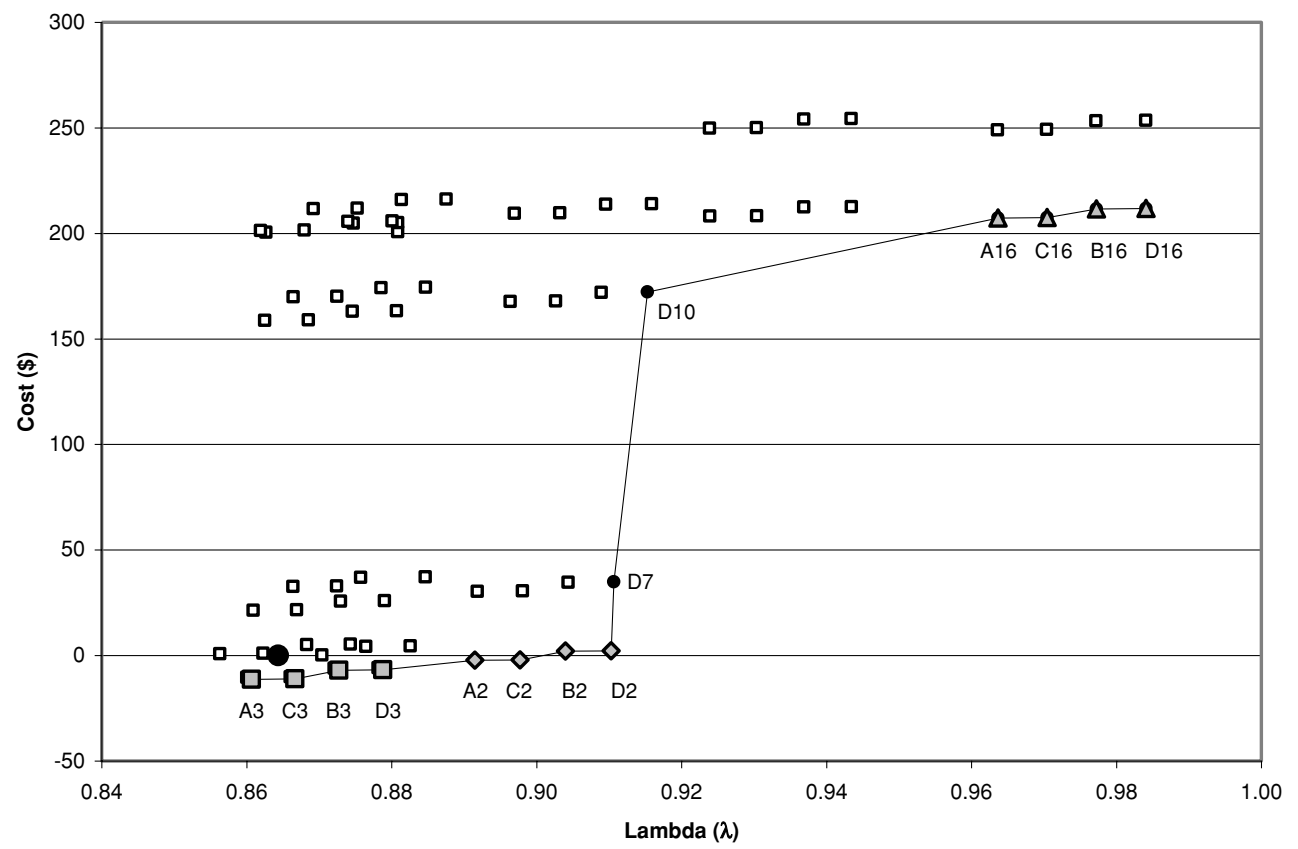

Figure 1. Results of cost-effectiveness analysis for Minam River stock of Snake River spring/summer run chinook salmon when $\mathrm{D}=0.553$ (D) delayed differential transportation mortality, the ratio of survival-and-return rates for smolts that were transported around dams to those that migrated downstream in the river). Annual cost is in millions of 2003 dollars. The line connects the set of cost-effective alternatives. The line segments illustrate $\Delta$ cost/ $\Delta \lambda$ between 2 adjacent alternatives. Grouping of cost-effective alternatives: those ending in 3 (shaded squares) include eliminating smolt transport, those ending in 2 (shaded diamonds) include maximizing transport, and those ending in 16 (shaded triangles) include dam breaching (full alternative descriptions are in Table 1). The baseline (large black circle) and other cost-ineffective alternatives (open squares) are shown to allow for comparison. 
Table 5. Cost-effective management alternatives and their marginal analysis for the Minam River index stock of Snake River spring/summer run chinook salmon for $D=0.553 .^{*}$

\begin{tabular}{lrrrrr}
$\begin{array}{l}\text { Alternative } \\
\text { number }\end{array}$ & $\lambda$ & Cost $(\$)$ & $\Delta \lambda$ & $\Delta$ cost $(\$)$ & \multicolumn{1}{c}{$\Delta \lambda$} \\
\hline A3 & 0.861 & -11.211 & N/A & \multicolumn{1}{c}{ N/A } & \multicolumn{1}{c}{ N/A } \\
C3 & 0.870 & -10.986 & 0.009 & 0.225 & \multicolumn{1}{c}{24.28} \\
B3 & 0.873 & -6.906 & 0.003 & 4.080 & 1466.15 \\
D3 & 0.882 & -6.681 & 0.009 & 0.225 & 23.93 \\
A2 & 0.891 & -2.250 & 0.009 & 4.431 & 473.32 \\
C2 & 0.901 & -2.025 & 0.010 & 0.225 & 23.40 \\
B2 & 0.904 & 2.055 & 0.003 & 4.080 & 1412.68 \\
D2 & 0.914 & 2.280 & 0.010 & 0.225 & 23.06 \\
D7 & 0.914 & 34.956 & 0.000 & 32.676 & 88148.73 \\
D10 & 0.919 & 172.259 & 0.005 & 137.303 & 29597.18 \\
A16 & 0.964 & 207.306 & 0.045 & 35.047 & 780.34 \\
C16 & 0.974 & 207.531 & 0.010 & 0.225 & 21.55 \\
B16 & 0.977 & 211.611 & 0.003 & 4.080 & 1301.05 \\
D16 & 0.988 & 211.836 & 0.011 & 0.225 & 21.23 \\
\hline
\end{tabular}

*Management alternatives are defined in Table 1 and in Methods section of text. Annual cost is in millions of 2003 dollars. Lambda ( $\lambda$ ) is the mean annual population growth rate arising from $a$ management alternative. The $\Delta$ cost and $\Delta \lambda$ are changes in annual cost and growth rate, respectively, of moving between cost-effective alternatives. The $\mathrm{D}$ is delayed differential transportation mortality, the ratio of survival-and-return rates for smolts that were transported around dams to those that migrated downstream in the river.

whereas most others were eliminated. The exceptions were alternatives D17, which incorporated tern removal, harvest elimination, dam breaching, and transportation at McNary Dam, and alternatives D14 and D15, which incorporated every measure but dam breaching and, in the case of D14, McNary Dam transportation. The highest achievable $\lambda$ with $D=1.0$ was 0.916 . The 11 costeffective alternatives when $D=0.7$ included most typical alternatives at the low-cost end (A3, C3, B3, D3), but at the high-cost end, the cost-effective set resembled that of $D=0.553$ because breaching alternatives dominated. When $D=0.4$, the cost-effective alternatives were the same as when $D=0.553$, but $\lambda$ s were higher in breaching alternatives and other alternatives where transportation was reduced.

Third, the cost-effectiveness analysis provided information on the cost of marginal increases in $\lambda$ (Table 5). For example, with $D=0.553$, compare 4 sequential costeffective alternatives (D7, D10, A16, and C16). Reservoir drawdown replaced flow augmentation when moving from alternative $\mathrm{D} 7$ to $\mathrm{D} 10$. This increased $\lambda$ by 0.005 $(0.54 \%)$ at a cost of $\$ 137.3$ million/year. In contrast, relative to D10, alternative A16 involved only dam breaching; it increased $\lambda$ by 0.045 (4.89\%) at a cost of $\$ 35.0$ million/year. Finally, moving from A16 to C16 added tern removal; this increased $\lambda$ by $0.01(1.24 \%)$ at a cost of just $\$ 225,000 /$ year.
Figure 1 illustrates these marginal changes, with $\Delta$ cost/ $\Delta \lambda$ equal to the slope of the line segment connecting 2 points. Graphically, relatively flat line segments represented low-cost ways of increasing $\lambda$ (e.g., moving from D10 to A16). Steep line segments represented the reverse (e.g., moving from D7 to D10). Notably, regardless of $D$ value, large changes in cost of increasing $\lambda$ came from the specific hydrosystem measures, many of which have extreme costs (e.g., dam breaching). Numerically, values of $\Delta \operatorname{cost} / \Delta \lambda$ increased as the cost per unit of $\lambda$ increased for adjacent alternatives in the cost-effective set (Table 5). The analysis made these trade-offs transparent.

Fourth, we report how the cost-effectiveness analysis changed with the 3 alternative costs of harvest elimination for $D=0.553$. Neither the cost-effective set nor its order changed with the low- or high-cost estimates of harvest elimination. At infinite cost the tribes were unwilling to sell fishing rights, and harvest-elimination alternatives (groups B and D) were thus not cost-effective. The analysis thus was robust to the low-to-high range of these costs, and only the infinite cost produced significant changes. This pattern held across the other $D$ values, with only one alternative dropping out of each cost-effective set while using the low and high costs of harvest restriction (when $D=1.0$ and 0.7 ) and no changes in the cost-effective set when $D=0.4$. This approach could be used to assess impacts of other cost uncertainties on the cost-effective set.

\section{Discussion}

Our integrated framework created a tool for considering management options for SRSS chinook salmon. Analyzing management alternatives is important because official and proposed salmon recovery plans are composed of multiple management measures. Our focus on alternatives preempts an extensive sensitivity analysis of individual measures, but Wilson (2003) develops this type of perspective with sensitivity, elasticity, and perturbation analyses for SRSS chinook salmon with population matrices.

Results of prior research show that $\lambda$ is sensitive to increases in first-year and estuarine survival rates (Kareiva et al. 2000; Wilson 2003). Kareiva et al. highlight the need for "management actions that might produce the desired improvements" in these survival rates. Removing Caspian Terns from the estuary was one such action because it increased $\lambda$ regardless of $D$ value (a result similar in magnitude to recent work by Good et al. (2007)), although its impact did vary with $D$.

Breaching the lower Snake River dams also could substantially increase $\lambda$, but its effectiveness depended on assumptions about $D$ value and latent mortality. Consistent with previous results (Wilson 2003), dam 
breaching markedly increased $\lambda$ when $D=0.553$. When we assumed $3 \%$ latent mortality, dam-breaching alternatives produce $\lambda$ gains of $20 \%$ or more and result in $\lambda>1$ for the Minam River stock. Larger latent mortality effects (5-6\%) were needed to raise other index stocks above that threshold.

Biological metrics other than $\lambda$ are available. The Interior Columbia Basin Technical Recovery Team (ICBTRT) used 4 population-level principles to assess ESA-listed salmonids: abundance, productivity, spatial structure, and diversity (ICBTRT 2005). The ICBTRT combined abundance (the number of spawners) and productivity $(\lambda)$ into a single metric: the risk of extinction in a 100year period. Unless current abundance is high and variability in population size is low, long-term extinction risk is $100 \%$ whenever $\lambda<1$ for an extended period. This makes long-term risk too blunt for our analysis, although developing a short-term extinction risk metric would be useful.

Three other qualifications are relevant for the biological analysis. One weakness of $\lambda$ was that, as a long-run metric, it failed to account for short-term productivity changes or the population's dynamic path of adjustment to a new equilibrium condition. This effect may be most severe with dam breaching, which would take several years to implement. A second limitation was our use of deterministic matrices, which tended to increase $\lambda$ relative to a stochastic model that incorporates environmental variability (Caswell 2001) and density dependence. Zabel et al. (2006) demonstrate the impact of density dependence in early life stages on population viability. Managers should consider precautionary adjustments for these dynamics. More conservative approaches, such as a goal of a $\lambda$ markedly greater than 1 , may be warranted. Third, CRiSP has been criticized for its spill-survival relationship (Marmorek \& Peters 1998) and its use of older salmon-passage data, but it remains the most data-driven and user-adaptable model for this research.

Cost-effectiveness analysis is useful in conservation planning because it identifies the least-cost way to achieve a biological goal. Our study is similar to analyses by Paulsen and Wernstedt (1995) and Garber-Yonts and Rettig (1997), but we used more recent models of salmon populations, estimates of $D$, and estimates of recovery costs. We also assessed some measures (dam breaching, Caspian Tern removal) that were not included in their analyses.

We applied the cost-minimization algorithm in Eq. 4 to identify inferior alternatives: for the Minam River index stock, $84 \%$ of alternatives across the $4 D$ values were eliminated. An example shows the utility of eliminating inferior alternatives. Consider the move between 2 costeffective alternatives (when $D=0.553$ ), B3 and D3 (Table 5; Fig. 1). The $\mathrm{B} 3$ alternative included harvest elimination and maximizing transportation.
To these, D3 added Caspian Tern removal for an increase in $\lambda$ of 0.01 and an incremental cost of $\$ 0.225$ million/year. By finding B3 and D3 as adjacent cost-effective alternatives, we eliminated 9 inferior alternatives whose incremental costs ranged from $<\$ 1$ million/year to over $\$ 200$ million/year. Savings from avoiding cost-ineffective alternatives can be large.

A policy maker could also consider the costs of marginal changes in $\lambda$ within the cost-effective set (Fig. 1; Table 5) as discussed in Results. More general perspectives are rendered by comparing cost-effective alternatives that are not adjacent. Consider 2 moves between nonadjacent alternatives with $D=0.553$. First, moving from A3 to D2 increased $\lambda$ by 0.053 at an incremental cost of $\$ 13.49$ million/year, an inexpensive move. Moving next from D2 to D10 caused the opposite effect: an increase of $\lambda$ of 0.005 at an incremental cost of almost $\$ 170$ million/year. Used in this way, the cost-effectiveness analysis focuses attention on particularly sensible alternatives.

Cost-ineffective alternatives may also be relevant to policy makers. A cost-ineffective alternative can be assessed by comparing its $(\lambda$, cost) outcome to that of a costeffective alternative. A policy maker might use this information to consider alternatives that are more expensive yet politically feasible. Again, the analysis makes such an approach to decision making transparent.

This integrated cost-effectiveness analysis can be applied to guide research toward developing biological or economic information on management measures that we did not consider because of a lack of data. Future research could yield data suitable for "filling in" matrix parameters, assessing the cost and biological effects of unstudied measures (e.g., spawning habitat restoration), or reducing uncertainty around some of the more critical elements (e.g., $D$ value, ocean survival rates, or latent mortality).

Several general qualifications remain. First, several management measures-such as dam breaching-would affect survival rates of other ESA-listed salmonid ESUs in the Columbia River Basin. In economic terms, a single input would generate several outputs, creating a joint production problem. This raises conceptual questions about the appropriate allocation of management measure or alternative costs. Guidelines exist for allocating costs of multioutput water projects in the context of benefitcost analysis (U.S. Water Resources Council 1983), but not for cost-effectiveness analysis. Should dam breaching costs simply be allocated equally among the 4 Snake River ESUs? Should these costs be further allocated to each of the stocks comprising an ESU?

Second, in addition to assisting salmon, a management measure may produce other economic goods and services as a by-product. For example, our analysis included the costs of lost hydropower production in dambreaching alternatives. Breaching, however, would also 
produce a free-flowing lower Snake River, from which economic benefits may be derived from new recreational opportunities or the aesthetic qualities of a natural river (Shogren et al. 1999). These are distinct from the salmonrecovery benefits. A complete cost-effectiveness analysis of salmon recovery would subtract the benefits of a free-flowing river from the costs of dam removal. Estimates of the recreational benefits of a (hypothetical) free-flowing lower Snake River range from \$193 to \$311 million annually (Loomis 2002), which is roughly sufficient to offset the estimated cost of breaching.

Third, we focused on quantitative metrics with welldeveloped impacts on $\lambda$ because data to support a full evaluation of spatial structure, diversity, and other salmonid life stages were unavailable. We omitted measures associated with hatchery management or freshwater habitat restoration because biological models were not available to estimate changes in survival rates at these life stages. Thus, our analytical baseline does not represent current management approaches (e.g., 2004 Biological Opinion) that acknowledge the importance of hatchery and habitat.

In sum, our research integrates biological and economic methods to develop a cost-effectiveness tool for assessing management alternatives for SRSS chinook salmon. The tool is a powerful way to eliminate alternatives from the cost-effective set, and it makes transparent the trade-off between biological benefits and economic costs of alternatives. Furthermore, using the cases of delayed differential mortality and the cost of harvest restrictions, the research illustrates how to incorporate biological or economic uncertainty via sensitivity analysis. This approach can be utilized by resource managers with responsibility for salmon recovery as new evidence becomes available on the biological effectiveness and economic cost of additional management measures. Linking biology and economics provides a valuable approach to science-based policy and management.

\section{Acknowledgments}

We thank J. Breck, D. Huppert, E. Hutchinson, M. McClure, J. Petersen, E. Rutherford, D. Tomberlin, K. van ' $t$ Veld, and 2 anonymous referees for useful discussions and helpful comments on the manuscript.

\section{Literature Cited}

Aillery, M., M. R. Moore, M. Weinberg, G. Schaible, and N. Gollehon. 1999. Salmon recovery measures in the Columbia River Basin: analysis of measures affecting agriculture. Marine Resource Economics 14:15-40.

American Rivers et al. v. NOAA Fisheries et al. U.S. District Court (for the District of Oregon). 2006. Opinion and order, CV 04-0061-RE.

Anderson, J., N. Beer, J. Hayes, S. Iltis, M. Moore, D. Salinger, P. Shaw, and R. Zabel. 2002. Columbia River Salmon Passage model
(CRiSP). Version 1.6. User manual and theory and calibration. School of Aquatic and Fishery Sciences. University of Washington, Seattle.

Budy, P., G. P. Thiede, N. Bouwes, C. E. Petrosky, and H. Schaller. 2002. Evidence linking delayed mortality of Snake River salmon to their earlier hydrosystem experience. North American Journal of Fisheries Management 22:35-51.

Caswell, H. 2001. Matrix population models: construction, analysis, and interpretation. 2nd edition. Sinauer Associates, Sunderland, Massachusetts.

Garber-Yonts, B., and R. B. Rettig. 1997. Cost-effective recovery of endangered Snake River salmon. Pages 198-203 in D. A. Hancock, D. C. Smith, A. Grant, and J. P. Beumer, editors. Developing and sustaining world fisheries resources. CSIRO, Brisbane, Queensland, Australia.

Good, T. P., M. M. McClure, B. P. Sandford, K. A. Barnas, D. M. Marsh, B. A. Ryan, and E. Casillas. 2007. Quantifying the effect of Caspian Tern predation on threatened and endangered Pacific salmon in the Columbia River estuary. Endangered Species Research 3:1121.

Heal, G. M., and E. B. Barbier. 2006. Valuing ecosystem services. The Economists' Voice 3(3): http://www.bepress.com/ev/vol3/ iss $3 / \operatorname{art} 2 /$.

Huppert, D. D. 1999. Snake River salmon recovery: quantifying the costs. Contemporary Economic Policy 17:476-491.

Huppert, D. D., D. L. Fluharty, E. Doyle, and A. Benyounes. 1996. Economics of Snake River recovery: a report to the National Marine Fisheries Service. College of Ocean and Fishery Sciences, University of Washington, Seattle.

ISAB (Independent Scientific Advisory Board). 2007. ISAB 2007-1 Latent mortality report. For the Northwest Power and Conservation Council, Columbia River Basin Indian Tribes, and National Marine Fisheries Service. ISAB, Portland. Oregon.

ICBTRT (Interior Columbia Basin Technical Recovery Team), Northwest Fisheries Science Center, National Marine Fisheries Service. 2005. Interior Columbia Basin TRT: viability criteria for application to interior Columbia Basin salmonid ESUs. ICBTRT, Seattle, Washington.

JCRMS (Joint Columbia River Management Staff). 2006. Joint staff report concerning commercial seasons for spring chinook, steelhead, sturgeon, shad, smelt, and other species and miscellaneous regulations for 2006. Oregon Department of Fish \& Wildlife, Salem, Oregon, and Washington Department of Fish \& Wildlife, Olympia, Washington. Available from http://wdfw.wa.gov/fish/crc/jan1806jointstaff.pdf (accessed March 2006).

Kareiva, P., M. Marvier, and M. McClure. 2000. Recovery and management options for spring/summer chinook salmon in the Columbia River Basin. Science 290:977-979.

Loomis, J. 2002. Quantifying recreation use values from removing dams and restoring free-flowing rivers: a contingent behavior travel cost demand model for the lower Snake River. Water Resources Research 38:1066-1073..

McClure, M. M., E. E. Holmes, B. L. Sanderson, and C. E. Jordan. 2003. A large-scale, multispecies status assessment: anadromous salmonids in the Columbia River Basin. Ecological Applications 13:964-989.

Marmorek, D. R., and C. N. Peters, editors. 1998. Plan for analyzing and testing hypotheses (PATH): preliminary decision analysis report on Snake River spring/summer chinook. ESSA Technologies, Vancouver, British Columbia.

Montgomery, C. A., G. M. Brown Jr., and D. M. Adams. 1994. The marginal cost of species preservation: the northern spotted owl. Journal of Environmental Economics and Management 26:111128.

NMFS (National Marine Fisheries Service). 1992. Endangered and threatened species; threatened status for Snake River spring/summer chinook salmon, threatened status for Snake River fall chinook salmon. Federal Register 57:14653-14663. 
National Wildlife Federation et al. v. National Marine Fisheries Service et al. 2005. U.S. District Court (District of Oregon). Opinion and order of remand, CV 01-640-RE.

Paulsen, C. M., and K. Wernstedt. 1995. Cost-effectiveness analysis for complex managed hydrosystems: an application to the Columbia River Basin. Journal of Environmental Economics and Management 28:388-400.

Radtke, H. D., C. N. Carter, and S. W. Davis. 2004. Economic evaluation of the Northern pikeminnow management program. Report. Pacific States Marine Fisheries Commission, Portland, Oregon.

Roby, D. D., D. E. Lyons, D. P. Craig, K. Collis, and G. Visser. 2003. Quantifying the effect of predators on endangered species using a bioenergetics approach: Caspian Terns and juvenile salmonids in the Columbia River estuary. Canadian Journal of Zoology 81:250-265.

Roughgarden, J. 2001. Guide to diplomatic relations with economists. Bulletin of the Ecological Society of America 82:85-88.

Shogren, J. F., et al. 1999. Why economics matters for endangered species protection. Conservation Biology 13:1257-1261.

USACE (U.S. Army Corps of Engineers). 2002. Lower Snake River juvenile salmon migration feasibility report and environmental impact statement. Appendix I: economics. USACE, Walla Walla, Washington.

U.S. Department of Energy, Bonneville Power Administration (BPA), U.S. Army Corps of Engineers, and U.S. Bureau of Reclamation. 1995. Columbia River system operation review-final environmental impact statement: main report, appendices A, C, E, and I. BPA, Portland, Oregon.
U.S. Department of the Interior, Bureau of Reclamation. 1999. Snake River flow augmentation impact analysis appendix. U.S. Bureau of Reclamation, Boise, Idaho.

U.S. Department of the Interior, Bureau of Reclamation. 2003. Pacific Northwest water acquisitions, 2001-2002. U.S. Bureau of Reclamation, Boise, Idaho.

U.S. Fish and Wildlife Service (USFWS). 2005. Caspian Tern management to reduce predation of juvenile salmonids in the Columbia River estuary, final environmental impact statement. USFWS, Portland, Oregon.

U.S. Water Resources Council. 1983. Economic and environmental principles and guidelines for water and related land resources implementation studies. U.S. Government Printing Office, Washington, D.C.

Williams, J. G., S. G. Smith, R. W. Zabel, W. D. Muir, M. D. Scheuerell, B. P. Sandford, D. M. Marsh, R. A. McNatt, and S. Achord. 2005. Effects of the federal Columbia River power system on salmonid populations. Technical memorandum NMFS-NWFSC-63. National Oceanic and Atmospheric Administration-National Marine Fisheries Service, Northwest Fisheries Science Center, Seattle.

Wilson, P. H. 2003. Using population projection matrices to evaluate recovery strategies for Snake River spring and summer chinook salmon. Conservation Biology 17:782-794.

Zabel, R. W., M. D. Scheuerell, M. M. McClure, and J. G. Williams. 2006. The interplay between climate variability and density dependence in the population viability of chinook salmon. Conservation Biology 20:190-200.

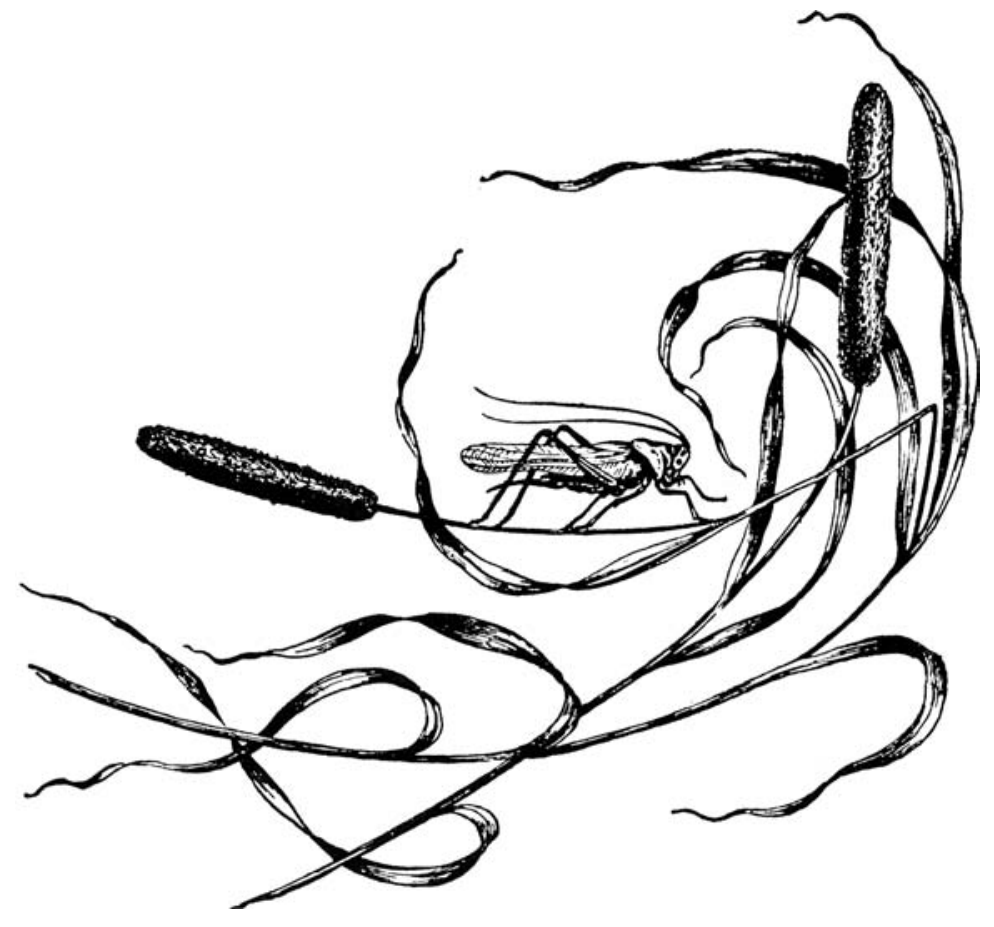

